\title{
Assessment of the Quality of Job Descriptions of Safety Jobs in the Saudi Companies
}

\author{
Hassan A. Al Abdullah ${ }^{1,2}$ (Corresponding author) \\ ${ }^{1}$ Department of Industrial Engineering, College of Engineering at Al-Qunfudah, \\ Umm Al-Qura University, Al-Qunfudah, Saudi Arabia \\ Telephone: +966-59-0005789Ｅmail: haabduallh@uqu.edu.sa \\ ${ }^{2}$ Department of Industrial Engineering, Faculty of Engineering, King Abdulaziz \\ University, Jeddah, Saudi Arabia
Mohamed A. Zytoon ${ }^{1,2}$
${ }^{1}$ Department of Industrial Engineering, Faculty of Engineering, King Abdulaziz University, Jeddah, Saudi Arabia
${ }^{2}$ Occupational Health and Air Pollution Department, High Institute of Public Health, Alexandria University, Alexandria, Egypt

Nader H. Al Sayed

Department of Industrial Engineering, Faculty of Engineering, King Abdulaziz University, Jeddah, Saudi Arabia

Received: November 29, 2017 Accepted: January 8, 2018 Published: January 15, 2018

doi:10.5296/jss.v4i1.12210 URL: https://doi.org/10.5296/jss.v4i1.12210

\begin{abstract}
The poor occupational safety and health (OSH) performance of many sectors in Saudi Arabia necessitates studying the reasons behind this performance. While other studies addressed many potential reasons, the objective of the current study is to investigate the quality of job descriptions of the safety jobs in Saudi Arabia. A sample of 69 job descriptions for several safety job titles and from different industrial or service sectors were analyzed to discover the important factors that may have an impact. The results revealed that there are some gaps in the design of the sampled job descriptions' components, particularly in the job information and the required qualifications for the jobs. The quality of job descriptions varied from one
\end{abstract}


industrial sector to another, with oil \& gas, petrochemicals and utilities sectors being in the top, and manufacturing, education/training, construction, and service/retail/distribution in the bottom in terms of job descriptions quality. There was no clear relationship between the safety job title and the quality of job descriptions. However, the required experience had positive impact on the quality of job descriptions of safety jobs. It is recommended that further studies covering a larger sample size of job descriptions to be conducted to obtain results that can be generalized and utilized in setting proper policies to improve the practices of the Saudi companies in the design of job descriptions of safety jobs and, hence, hiring the appropriate safety professionals.

Keywords: Job description; Safety jobs; Safety professionals; Saudi Arabia

\section{Introduction}

Recently, there has been a growing interest in occupational safety and health (OSH) in Saudi Arabia. The official bodies necessitate that companies adopt OSH policies and also to pay great attention to the importance of safety means (Al-Ghamri, 2017). The reasons behind such growing interest in OSH are many, of which the low level of safety performance found in many studies (Taylan et al., 2017; Alsubaie, 2017; Ahmed et al., 2017; Al-Qubaisi, 2016; Mosly, 2015; Alolah et al., 2014; Noweir et al., 2013; Al Haadir and Panuwatwanich, 2011; Hassanain and Al-Mudhei, 2006) is an important one. There were some efforts to explain the poor OSH performance of the Saudi companies. For instance, Noweir et al. (2013) discussed several factors, such as improper enforcement of regulations, lack of information about OSH needs, lack of coordination among official bodies related to $\mathrm{OSH}$, and lack of specialized safety professionals. Other researchers linked that performance to the organizations' safety culture (Alasmari et al., 2012, Alqubaisi, 2017) and inefficient OSH management systems (Suresh et al., 2017; Al-Darrab et al., 2013; Al Haadir and Panuwatwanich, 2011).

All of the aforementioned factors, undoubtedly, have an obvious role in the OSH performance. Nevertheless, the presence of competent safety specialists has a significant impact on the safety culture of organizations (Wu et al., 2010; Wu et al., 2007; Wu, 2004, Tweeddale, 2001), which is "the attitude, beliefs, perceptions and values that employees share in relation to safety in the workplace (Cox and Cox, 1991)." The presence of competent safety specialists is a key component of any OSH management systems. It is worth mentioning that Noweir et al. (2013) found that only approximately third of the companies in their sample had safety specialist. On the other hand, Al-Ghamri (2017) recommended that qualified OSH personnel should be hired to improve the OSH performance of small Saudi companies. However, this cannot be achieved unless the roles and responsibilities of the safety professional in an organization as well as the required competencies and qualifications are well-defined. This is normally documented in the job description. Thus, the first step towards hiring the appropriate safety professional is to accurately design the related job description.

A job description is a written document that outlines the duties, responsibilities, contributions, behaviors, outcomes and required qualifications for a specific job in an organization (Rohr, 2016). The job description is, therefore, the detailed requirement of a specific job. The Job 
description is the outcome of detailed job analysis. Job descriptions are an essential tool in the recruitment and selection process. They describe the skills and knowledge required for the position as well as personal abilities and physical requirements (Gan and Kleiner, 2005). Additionally, job descriptions can be used by safety educators to get up-to-date information about the emerging competencies that should be attained by the safety professionals to cover them within the educational curricula.

Unless the job descriptions of safety positions in an organization are properly designed incompetent safety professionals will be hired and, consequently, the OSH management system will be seriously affected resulting in lower performance. Based on this, the authors suggest that the job description of a safety position can be considered as a leading indicator of OSH performance of an organization. It is, therefore, important to study the quality of job description of safety positions in the Saudi companies. The objective of the current study is to investigate the appropriateness of the elements of job descriptions of safety positions in a random sample of Saudi companies from several sectors.

\section{Methods}

\subsection{Sampling Procedure}

Before sample collection, it was necessary to know the titles of safety jobs commonly utilized in the Saudi companies. Examining hundreds of job descriptions and job announcements of positions related to the field of OSH revealed that the job titles related to the safety profession and used by the Saudi companies were safety inspector, safety trainer, safety specialist, safety engineer, loss prevention engineer, safety supervisor, safety advisor, safety coordinator, safety officer and safety manager. Accordingly, these titles were used as keywords for searching or requesting the related job descriptions.

The investigated job descriptions were collected from many sources, mainly job advertisements of well-known recruitment agencies (Pitt \& Mewburn, 2016; Park et al., 2009; Hall-Ellis, 2006), companies' human resources or safety departments, and the companies' official websites (Teare et al., 2017; Weiss-Gal \& Liven, 2010).

A total number of 69 job descriptions were collected during the period from March to September 2017. They were classified based on the job title and the industrial sector before further processing. The industrial sectors were classified as oil and gas, petrochemicals, manufacturing, construction, utilities, education, and service/retail/distribution. The sample characteristics are presented in Table 1.

\subsection{Assessment of Job Description}

There is no unified form to write a job description in. However, some main components existing in all job descriptions, such as job information, duties and responsibilities, and requirements (qualifications) of the job (Jerabek, 2003). The details of these components vary from company to another. Nevertheless, all of them should include the title of the job, the purpose of the job, working conditions, principal duties and responsibilities, as well as 
education, professional certification, specialized knowledge, technical skills, interpersonal skills and experience (Smith, 2015; Cushway, 2008). For easy assessment of job descriptions, the components were assessed based on the following components:

1. Job information (INFO): this includes job title (INFO1), the purpose of the job (INFO2) and working conditions (INFO3).

2. Job roles and responsibilities (ROLE)

3. Job requirements and qualifications (QUAL): this include education (QUAL1), professional certification (QUAL2), specialized knowledge (QUAL3), technical skills (QUAL4), personal abilities (QUAL5) and experience (QUAL6).

The collected job descriptions were assessed via these three main components using a 5-point Likert scale. The scores 5, 4, 3, 2 and 1 were given when the quality of a component of the job description was excellent, good, moderate, poor and not existing, respectively. The scores were given based on the presence or absence of the related details or subcomponents. Three persons participated in the assessment: one safety academician, one safety practitioner and one human resources academician. Their scores of an element were averaged and rounded to the nearest whole number.

Table 1. Job description sample characteristics

\begin{tabular}{|c|c|c|c|}
\hline Characteristic & $\begin{array}{c}\text { Number of job } \\
\text { descriptions }\end{array}$ & Characteristic & $\begin{array}{c}\text { Number of job } \\
\text { descriptions }\end{array}$ \\
\hline \multicolumn{2}{|l|}{ Safety job title: } & \multicolumn{2}{|l|}{ Industrial sector: } \\
\hline Safety engineer (SE) & $15(21.7 \%)$ & Oil \& gas (OGS) & $19(27.5 \%)$ \\
\hline Safety specialist (SSp) & $9(13.0 \%)$ & $\begin{array}{c}\text { Service/retail/distribution } \\
\text { (SRD) }\end{array}$ & $13(18.8 \%)$ \\
\hline Safety manager (SM) & $9(13.0 \%)$ & Petrochemicals (PET) & $12(17.4 \%)$ \\
\hline Safety advisor (SA) & $7(10.1 \%)$ & Construction (CON) & $9(13.0 \%)$ \\
\hline Safety inspector (SI) & $5(7.2 \%)$ & Education/training (EDU) & $6(8.7 \%)$ \\
\hline Safety supervisor (SS) & $5(7.2 \%)$ & Utilities (UTL) & $6(8.7 \%)$ \\
\hline Safety coordinator (SC) & $5(7.2 \%)$ & Manufacturing (MAN) & $4(5.8 \%)$ \\
\hline Safety officer (SO) & $5(7.2 \%)$ & \multicolumn{2}{|l|}{ Years of experience: } \\
\hline Safety trainer (ST) & $5(7.2 \%)$ & $0-5$ years & $37(53.6 \%)$ \\
\hline $\begin{array}{l}\text { Loss prevention engineer } \\
\text { (LP) }\end{array}$ & $4(5.8 \%)$ & $6-10$ years & $24(34.8 \%)$ \\
\hline & & $>10$ years & $8(11.6 \%)$ \\
\hline Total number & \multicolumn{3}{|l|}{$69(100 \%)$} \\
\hline
\end{tabular}




\subsection{Statistical Analysis}

This study investigates the overall quality of job descriptions of safety jobs, as well as whether the job title, industrial sector and required experience have an impact on the quality of the sampled job descriptions. Descriptive statistics, such as mean, standard deviation (SD), the coefficient of variation (CV) and interquartile range (IQR) were utilized in the analysis. The required experience for the job (in years) was treated as a continuous variable and, hence, linear regression was used to test its impact on the quality of job descriptions. A 95\% confidence level was used to test the statistical significance when needed.

\section{Results and discussion}

\subsection{Overall Evaluation of Job Descriptions}

The complete assessment scores are presented in Table 2 and the mean scores are shown in Figure 1. The overall mean score of the collected 69 job descriptions was $3.8 \pm 0.7$ out of 5.0. This mean score is indicative of overall above average quality of job descriptions of the safety positions in the Saudi companies although some of the sampled job descriptions were well-written and others were poorly written (the range of mean score was $2.2-4.8$ ). The poorly designed job descriptions are unlikely to enable hiring competent safety professionals. As a result, the OSH management systems or the safety culture of the Saudi companies were negatively affected (Tweeddale, 2001) with the final result of poor OSH performance as discussed in the previous sections.

Table 2. Evaluation of the components of the sampled job descriptions of safety positions

\begin{tabular}{|c|c|c|c|c|c|c|c|}
\hline $\begin{array}{c}\text { Job } \\
\text { description } \\
\text { number }\end{array}$ & $\begin{array}{c}\text { Safety } \\
\text { Job }\end{array}$ & $\begin{array}{c}\text { Industrial } \\
\text { sector }\end{array}$ & $\begin{array}{c}\text { Experience } \\
\text { (years) }\end{array}$ & $\begin{array}{c}\text { Job } \\
\text { Information } \\
\text { (INFO) }\end{array}$ & $\begin{array}{c}\text { Roles \& } \\
\text { Responsibilities } \\
\text { (ROLE) }\end{array}$ & $\begin{array}{c}\text { Qualification } \\
\text { (QUAL) }\end{array}$ & $\begin{array}{c}\text { Overall } \\
\text { Mean }\end{array}$ \\
\hline 1 & SO & MAN & 5 & 3 & 5 & 3 & 3.7 \\
\hline 2 & SO & MAN & 7 & 4 & 3 & 4 & 3.7 \\
\hline 3 & SO & SRD & 5 & 3 & 5 & 2 & 3.2 \\
\hline 4 & SO & CON & 6 & 3 & 2 & 3 & 2.4 \\
\hline 5 & SO & CON & 10 & 4 & 3 & 4 & 3.7 \\
\hline 6 & SA & PET & 20 & 4 & 4 & 5 & 4.3 \\
\hline 7 & SA & PET & 1 & 4 & 5 & 3 & 4.0 \\
\hline 8 & SA & OGS & 1 & 4 & 5 & 4 & 4.2 \\
\hline 9 & SA & OGS & 10 & 5 & 5 & 5 & 5.0 \\
\hline 10 & SA & OGS & 0 & 3 & 5 & 2 & 3.6 \\
\hline 11 & SA & CON & 5 & 3 & 4 & 4 & 3.7 \\
\hline
\end{tabular}




\begin{tabular}{|c|c|c|c|c|c|c|c|}
\hline 12 & $\mathrm{SA}$ & PET & 8 & 3 & 5 & 3 & 3.7 \\
\hline 13 & $\mathrm{SS}$ & OGS & 8 & 3 & 5 & 4 & 4.2 \\
\hline 14 & SS & SRD & 3 & 3 & 4 & 2 & 2.8 \\
\hline 15 & SS & SRD & 0 & 4 & 5 & 1 & 3.4 \\
\hline 16 & $\mathrm{SS}$ & $\mathrm{CON}$ & 10 & 4 & 5 & 3 & 4.0 \\
\hline 17 & $\mathrm{SS}$ & MAN & 5 & 3 & 5 & 3 & 3.7 \\
\hline 18 & $\mathrm{SC}$ & UTL & 2 & 3 & 4 & 3 & 3.5 \\
\hline 19 & $\mathrm{SC}$ & OGS & 5 & 4 & 4 & 3 & 3.6 \\
\hline 20 & $\mathrm{SC}$ & OGS & 5 & 4 & 5 & 5 & 4.7 \\
\hline 21 & $\mathrm{SC}$ & OGS & 3 & 3 & 3 & 2 & 2.8 \\
\hline 22 & $\mathrm{SC}$ & UTL & 2 & 3 & 5 & 4 & 3.9 \\
\hline 23 & SI & PET & 19 & 4 & 5 & 5 & 4.6 \\
\hline 24 & SI & OGS & 6 & 3 & 5 & 3 & 3.8 \\
\hline 25 & SI & SRD & 5 & 3 & 5 & 3 & 3.8 \\
\hline 26 & SI & SRD & 6 & 3 & 3 & 2 & 2.4 \\
\hline 27 & SI & $\mathrm{CON}$ & 5 & 5 & 5 & 3 & 4.3 \\
\hline 28 & $\mathrm{SSp}$ & UTL & 3 & 3 & 4 & 4 & 3.8 \\
\hline 29 & $\mathrm{SSp}$ & UTL & 5 & 3 & 4 & 3 & 3.4 \\
\hline 30 & $\mathrm{SSp}$ & OGS & 10 & 5 & 5 & 5 & 5.0 \\
\hline 31 & $\mathrm{SSp}$ & SRD & 10 & 4 & 3 & 3 & 3.3 \\
\hline 32 & $\mathrm{SSp}$ & SRD & 3 & 3 & 5 & 1 & 3.1 \\
\hline 33 & $\mathrm{SSp}$ & UTL & 2 & 4 & 5 & 3 & 4.1 \\
\hline 34 & $\mathrm{SSp}$ & $\mathrm{CON}$ & 10 & 4 & 5 & 5 & 4.7 \\
\hline 35 & $\mathrm{SSp}$ & PET & 3 & 4 & 5 & 4 & 4.3 \\
\hline 36 & $\mathrm{SSp}$ & PET & 10 & 4 & 5 & 5 & 4.7 \\
\hline 37 & LP & OGS & 10 & 5 & 5 & 4 & 4.7 \\
\hline 38 & LP & OGS & 10 & 5 & 5 & 5 & 5.0 \\
\hline 39 & LP & SRD & 0 & 4 & 5 & 1 & 3.4 \\
\hline 40 & LP & SRD & 5 & 3 & 2 & 3 & 2.4 \\
\hline 41 & $\mathrm{SE}$ & PET & 15 & 4 & 5 & 5 & 4.7 \\
\hline 42 & $\mathrm{SE}$ & PET & 1 & 3 & 4 & 3 & 3.3 \\
\hline
\end{tabular}




\begin{tabular}{|c|c|c|c|c|c|c|c|}
\hline 43 & $\mathrm{SE}$ & PET & 20 & 4 & 5 & 5 & 4.5 \\
\hline 44 & $\mathrm{SE}$ & OGS & 2 & 4 & 5 & 4 & 4.4 \\
\hline 45 & $\mathrm{SE}$ & OGS & 4 & 4 & 5 & 4 & 4.4 \\
\hline 46 & $\mathrm{SE}$ & OGS & 1 & 4 & 5 & 2 & 3.6 \\
\hline 47 & $\mathrm{SE}$ & OGS & 10 & 5 & 5 & 5 & 5.0 \\
\hline 48 & $\mathrm{SE}$ & OGS & 9 & 4 & 5 & 4 & 4.2 \\
\hline 49 & $\mathrm{SE}$ & EDU & 0 & 4 & 5 & 2 & 3.8 \\
\hline 50 & $\mathrm{SE}$ & $\mathrm{CON}$ & 0 & 4 & 5 & 3 & 3.9 \\
\hline 51 & $\mathrm{SE}$ & $\mathrm{CON}$ & 6 & 2 & 2 & 2 & 2.2 \\
\hline 52 & $\mathrm{SE}$ & MAN & 0 & 3 & 5 & 3 & 3.4 \\
\hline 53 & $\mathrm{SE}$ & PET & 12 & 4 & 5 & 5 & 4.5 \\
\hline 54 & $\mathrm{SE}$ & PET & 8 & 3 & 5 & 4 & 3.9 \\
\hline 55 & $\mathrm{SE}$ & PET & 10 & 4 & 5 & 5 & 4.7 \\
\hline 56 & SM & UTL & 10 & 5 & 5 & 5 & 5.0 \\
\hline 57 & SM & SRD & 10 & 4 & 5 & 4 & 4.3 \\
\hline 58 & $\mathrm{SM}$ & SRD & 5 & 4 & 2 & 3 & 2.9 \\
\hline 59 & $\mathrm{SM}$ & OGS & 5 & 5 & 5 & 5 & 4.7 \\
\hline 60 & $\mathrm{SM}$ & OGS & 18 & 5 & 5 & 4 & 4.7 \\
\hline 61 & SM & EDU & 15 & 5 & 5 & 5 & 4.7 \\
\hline 62 & $\mathrm{SM}$ & SRD & 5 & 5 & 5 & 3 & 4.4 \\
\hline 63 & $\mathrm{SM}$ & SRD & 12 & 4 & 4 & 3 & 3.7 \\
\hline 64 & $\mathrm{SM}$ & $\mathrm{CON}$ & 5 & 3 & 2 & 3 & 2.7 \\
\hline 65 & $\mathrm{ST}$ & EDU & 4 & 5 & 5 & 2 & 4.1 \\
\hline 66 & $\mathrm{ST}$ & OGS & 7 & 3 & 4 & 3 & 3.3 \\
\hline 67 & $\mathrm{ST}$ & EDU & 3 & 3 & 2 & 2 & 2.3 \\
\hline 68 & $\mathrm{ST}$ & EDU & 3 & 3 & 2 & 2 & 2.3 \\
\hline 69 & $\mathrm{ST}$ & EDU & 10 & 4 & 3 & 4 & 3.7 \\
\hline
\end{tabular}

Figure 1 shows that the mean scores of the three main components of the job description, i.e., INFO, ROLE and QUAL, were 3.7 $\pm 0.7,4.4 \pm 1.0$ and 3.3 \pm 1.0 , respectively, indicating that the sampled companies gave the greatest attention to roles and responsibilities when writing the job descriptions of safety positions. This positive point was, however, counteracted by low quality of other components of job description. For instance, the qualifications' component 
was, generally, poorly written. Studying the details of the component QUAL, it was found that education (QUAL1), specialized knowledge (QUAL3), technical skills (QUAL4) and experience (QUAL5) were moderately written. However, the other requirements, i.e., professional certification (QUAL2) and personal abilities (QUAL6) were not properly shown in most of the job descriptions, resulting in lowering the overall score of the QUAL component to slightly above average. The absence of professional certification requirement in many job descriptions may be explained by the absence of professional safety organizations in Saudi Arabia, except for the General Directorate of Civil Defense which provides certification only in firefighting. Furthermore, the awareness of the importance of personal abilities is probably low although many studies found that they are among the most important competencies of the safety professionals (Chang et al., 2012; Leemann, 2005; Blair, 2004). The low quality of the qualifications' component constitutes a serious weakness in the safety awareness of the Saudi companies as it means that they will not hire the appropriate safety professionals to hire (Wu et al., 2010). Many plant owners or managers underestimate the importance of hiring qualified safety professionals as they think that it is an easy task that can be handled by technical staff from other departments such as maintenance department (Noweir et al., 2013).

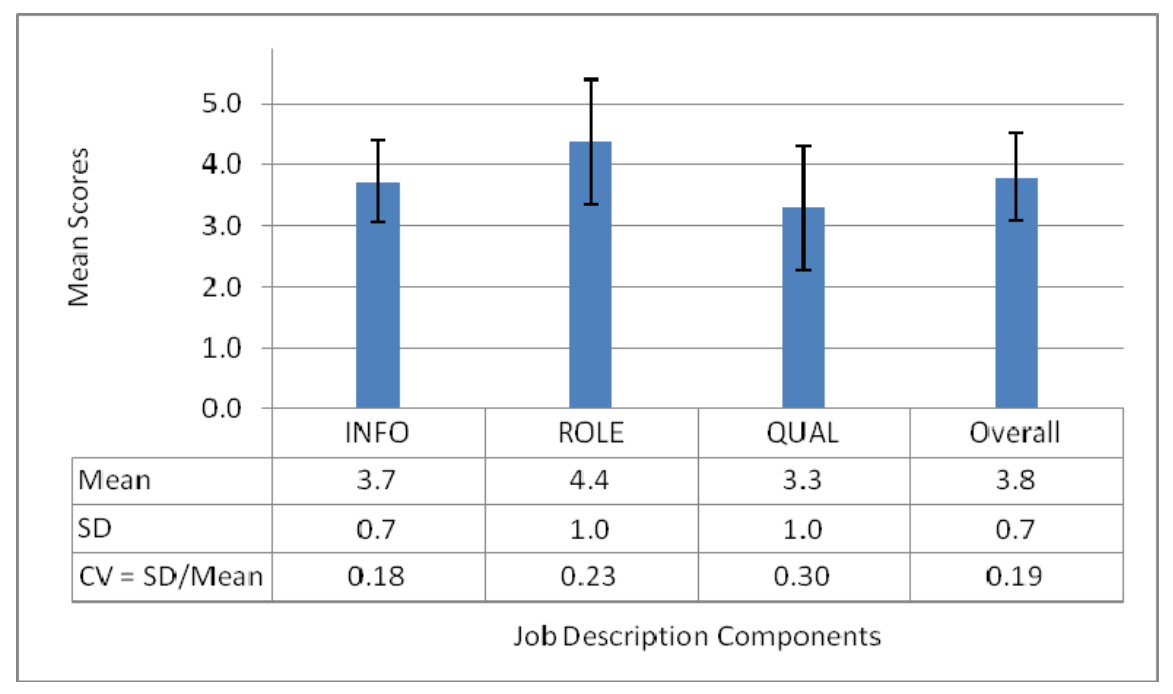

Figure 1. Average components' scores of the job descriptions of safety positions

The component job information (INFO) had above average score (3.7). The analysis of its attributes revealed that this score was elevated by the presence of the job title (INFO1) in all job descriptions. The other two attributes, i.e., job purpose (INFO2) and work conditions (INFO3), were, however, unclearly shown in the job descriptions. The latter two attributes are important characteristics that should be considered in job design as they have significant impact on job satisfaction as described in job design theories (Bakker and Demerouti, 2014; Bakker and Demerouti, 2011; Humphrey et al., 2007; Morgeson and Humphrey, 2006; Hackman \& Oldham, 1980; Hackman \& Oldham, 1976). Human resources managers should keep in mind that the safety professionals have a certain level of knowledge about job design theories, and they expect to see these important job design elements in the job descriptions. Unless they find them, they are likely to develop a negative impression about the safety 
culture of the organization. This may result in limited opportunities of hiring highly qualified safety professionals. Furthermore, the current job holders may develop job dissatisfaction and reduced performance if they find the actual job purpose and working conditions are different from what they expected.

Comparing the coefficients of variation for the scores of the components, Figure 1 shows that the variation among the sampled job descriptions was highest in the component QUAL (CV = $0.30, \mathrm{IQR}=1.5))$ and lowest in INFO $(\mathrm{CV}=0.18, \mathrm{IQR}=0.7)$ with $\mathrm{ROLE}$ in between $(\mathrm{CV}=$ $0.23, \mathrm{IQR}=1.0)$. For overall means, the variation was relatively low $(\mathrm{CV}=0.19, \mathrm{IQR}=1.0)$.

To test the consistency of the quality of the elements of the sampled job descriptions, the Pearson's correlation coefficient was used. Table 3 shows that correlation between the two elements QUAL and INFO was stronger than that between ROLE and INFO, and the latter was stronger than that between QUAL and ROLE, although all of the correlations were significant. This is an indication that the quality levels of the three elements were positively correlated in a considerable number (but not all) of job descriptions. On the other hand, the correlations between the overall quality and the job description elements were strongly positive.

Table 3. Correlations among the sampled job description's elements (Pearson's correlation coefficient)

\begin{tabular}{|c|c|c|c|}
\hline & INFO & ROLE & QUAL \\
\hline ROLE & $0.444 * *$ & & \\
\hline QUAL & $0.552 * *$ & $0.340 *$ & \\
\hline Overall & $0.793 * *$ & $0.762 * *$ & $0.819 * *$ \\
\hline
\end{tabular}

* $P$-value $<0.001 \quad * * P$-value $<0.001$

\subsection{Evaluation of Job Description Components According to Industrial Sector}

The influence of industrial sector on safety jobs description is presented in Table 4 and the averages of industries are shown in Figure 2. The highest mean scores were observed in job descriptions from petrochemicals industries (4.3 \pm 0.4$)$, oil \& gas industries (4.2 \pm 0.7$)$ and utility companies (4.0 \pm 0.6 ). The high quality of the job descriptions from the petrochemicals and oil \& gas industries is mainly attributed to the long experience of the two leading companies in Saudi Arabia - ARAMCO and SABIC - both have established their OSH management systems earlier than any other company in Saudi Arabia (Kadasah, 2015; Al-Darrab et al., 2013), and many other companies consider both as benchmarks in OSH performance. It is expected that the high safety performance of the petrochemicals and the oil $\&$ gas companies was reflected in the quality of job descriptions of the safety jobs. On the other hand, in spite of the poor safety culture found by Al-Qubaisi (2016) in a utility company based on data of the period $2010-2014$, the quality of job descriptions from this sector was high, reflecting a recent interest in establishing OSH management systems. This is evident particularly in the Saudi Electricity Company that has started the system (Aburass, 2018). 
Table 4. Evaluation of job description components according to industrial sector

\begin{tabular}{|c|c|c|c|c|}
\hline Safety Job title & Statistic & $\begin{array}{c}\text { Job Information } \\
\text { (INFO) }\end{array}$ & $\begin{array}{c}\text { Roles \& } \\
\text { Responsibilities }\end{array}$ & $\begin{array}{c}\text { Qualification } \\
\text { (QUAL) }\end{array}$ \\
\hline Petrochemicals (PET) & Mean & 3.8 & 4.8 & 4.2 \\
& SD & 0.4 & 0.4 & 0.9 \\
\hline Oil \& gas (OGS) & Mean & 4.2 & 4.8 & 3.8 \\
& SD & 0.7 & 0.5 & 1.0 \\
\hline Utilities (UTL) & Mean & 3.7 & 4.5 & 3.7 \\
& SD & 0.7 & 0.5 & 0.8 \\
\hline Manufacturing (MAN) & Mean & 3.1 & 4.5 & 3.3 \\
& SD & 0.6 & 1.0 & 0.6 \\
\hline Education/training (EDU) & Mean & 3.9 & 3.7 & 2.8 \\
& SD & 0.9 & 1.5 & 1.1 \\
\hline Construction (CON) & Mean & 3.6 & 3.7 & 3.2 \\
& SD & 0.7 & 1.4 & 0.9 \\
\hline Service/retail/distribution & Mean & 3.5 & 4.1 & 2.4 \\
(SRD) & SD & 0.7 & 1.2 & 0.9 \\
\hline
\end{tabular}

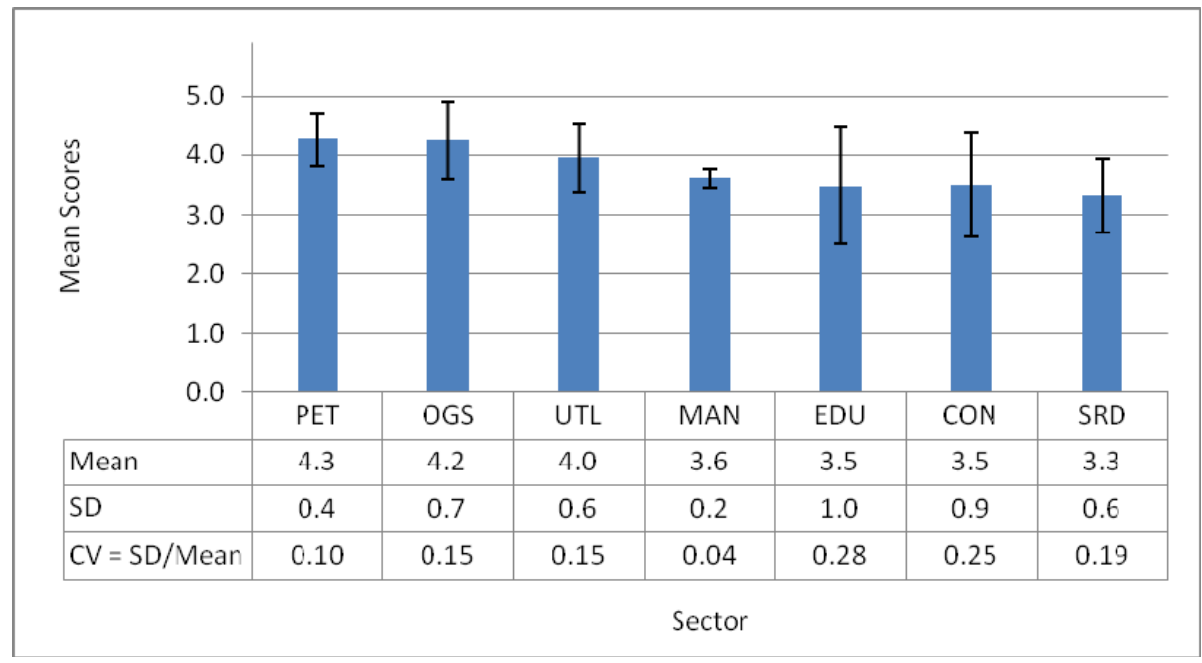

Figure 2. Mean score of job descriptions according to industrial sector

The job descriptions from the other sectors had moderate quality, such as manufacturing (3.6 \pm 0.2$)$, education/training (3.5 \pm 1.0$)$, construction (3.5 \pm 0.9 ) and SRD (3.3 \pm 0.6$)$. The low quality of job descriptions from these sectors is in line with the low OSH performance found in other studies related to manufacturing sector (Al-Ghamri, 2017; Noweir, et al., 2013) and construction sector (Mosly, 2015; Al Haadir and Panuwatwanich, 2011). Furthermore, Kadasah (2015) concluded that the service sector and educational institutions came far after manufacturing sector in OSH performance. The relatively poor performance of these sectors might have associated the poor job descriptions of safety positions. 
It was mentioned in the previous section that the overall quality of the job description component QUAL was found lower than other components. Table 4 shows that this was more evident in education, construction, SRD and, surprisingly, oil \& gas sectors. In other sectors, its quality was equal or higher than the INFO component. Furthermore, the quality of the component ROLE was higher than the remaining two components (INFO and QUAL) in job descriptions from all sectors except for education/training sector, where INFO was scored better.

Figure 2 shows that the $\mathrm{CV}$ values of the scores of job descriptions from the least three sectors were higher than other sectors, indicating less consistency among those sectors in writing the job descriptions of safety jobs.

\subsection{Evaluation of Job Description Components According to Safety Job Title}

The mean scores of job description components according to job title are presented in Table 5 . Additionally, the overall mean score of job descriptions of the safety job titles are illustrated in Figure 3, which shows that the job descriptions of the job titles SM, SA, SSp and SE were very good $(\geq 4.0)$ whereas those of the job titles SO and ST had slightly above average scores ( 3.3 and 3.1, respectively). The scores of the titles LP, SI, SC and SS were well-above average (from 3.6 to 3.9). These results do not allow for a solid conclusion about the relationship between the job title and the quality of job description. For instance, the job titles SM (managerial position) and SA (supervisory position) had the highest scores among others. This would be explained by a greater attention given from Saudi companies to the job descriptions of the higher safety positions. The other managerial and supervisory (SO, SS and SC) titles had the same high scores. However, this was not the case as the job descriptions of the latter three job titles were lower in quality. Furthermore, technical safety jobs such as SI and SSp were better than the higher safety jobs SO, SS and SC. Nonetheless, it is noted that the best job description score was for the title SM and the lowest was for the title ST.

Figure 3 shows that the variability of job description scores was low for the job titles SA (CV $=0.12)$ and SS $(\mathrm{CV}=0.15)$, whereas it was large for LP $(\mathrm{CV}=0.30), \mathrm{ST}(\mathrm{CV}=0.25)$ and SI $(C V=0.22)$. Variability of other titles scores were in between $(C V=0.17-0.20)$. In line with what was mentioned in the previous subsection, the jobs with the higher mean scores showed relatively higher score variability, as predicted from the values of CV (Fig. 3), indicating that not all of the companies having these jobs had a well-defined job description.

Considering the quality of job description components, Table 5 shows variable trends within the same safety job title. For instance, the job description quality was highest for the job title SM, based on overall assessment (4.1 \pm 0.8$)$, and based on the components INFO (4.4 \pm 0.6$)$ and QUAL (3.7 \pm 0.8$)$. However, it was ranked seventh based on the quality of the component ROLE (4.2 \pm 1.3$)$. On the other hand, the job description quality was lowest for the job title ST,

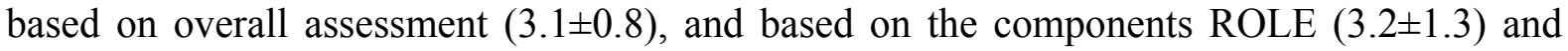
QUAL (2.6 \pm 0.8$)$. However, it was ranked sixth (out of ten) based on the quality of the component INFO (3.6 \pm 0.9$)$. 
Table 5. Evaluation of job description components according to safety job title

\begin{tabular}{|c|c|c|c|c|}
\hline Safety Job title & Statistic & $\begin{array}{c}\text { Job Information } \\
\text { (INFO) }\end{array}$ & $\begin{array}{c}\text { Roles \& } \\
\text { Responsibilities } \\
\text { (ROLE) }\end{array}$ & $\begin{array}{c}\text { Qualification } \\
\text { (QUAL) }\end{array}$ \\
\hline \multirow[t]{2}{*}{ Safety Manager (SM) } & Mean & 4.4 & 4.2 & 3.7 \\
\hline & SD & 0.6 & 1.3 & 0.8 \\
\hline \multirow[t]{2}{*}{ Safety Advisor (SA) } & Mean & 3.8 & 4.7 & 3.7 \\
\hline & $\mathrm{SD}$ & 0.7 & 0.5 & 1.0 \\
\hline \multirow[t]{2}{*}{ Safety Engineer (SE) } & Mean & 3.8 & 4.7 & 3.6 \\
\hline & SD & 0.7 & 0.8 & 1.1 \\
\hline \multirow[t]{2}{*}{ Safety Specialist (SSp) } & Mean & 3.9 & 4.6 & 3.7 \\
\hline & SD & 0.6 & 0.7 & 1.2 \\
\hline \multirow[t]{2}{*}{ Loss Prevention (LP) } & Mean & 4.2 & 4.3 & 3.3 \\
\hline & SD & 1.1 & 1.5 & 1.6 \\
\hline \multirow[t]{2}{*}{ Safety Inspector (SI) } & Mean & 3.5 & 4.6 & 3.2 \\
\hline & $\mathrm{SD}$ & 0.8 & 0.9 & 1.2 \\
\hline \multirow[t]{2}{*}{ Safety Coordinator (SC) } & Mean & 3.5 & 4.2 & 3.3 \\
\hline & SD & 0.5 & 0.8 & 1.0 \\
\hline \multirow[t]{2}{*}{ Safety Supervisor (SS) } & Mean & 3.4 & 4.8 & 2.6 \\
\hline & $\mathrm{SD}$ & 0.6 & 0.4 & 1.2 \\
\hline \multirow[t]{2}{*}{ Safety Officer (SO) } & Mean & 3.3 & 3.6 & 3.1 \\
\hline & SD & 0.7 & 1.3 & 1.0 \\
\hline \multirow[t]{2}{*}{ Safety Trainer (ST) } & Mean & 3.6 & 3.2 & 2.6 \\
\hline & SD & 0.9 & 1.3 & 0.8 \\
\hline
\end{tabular}

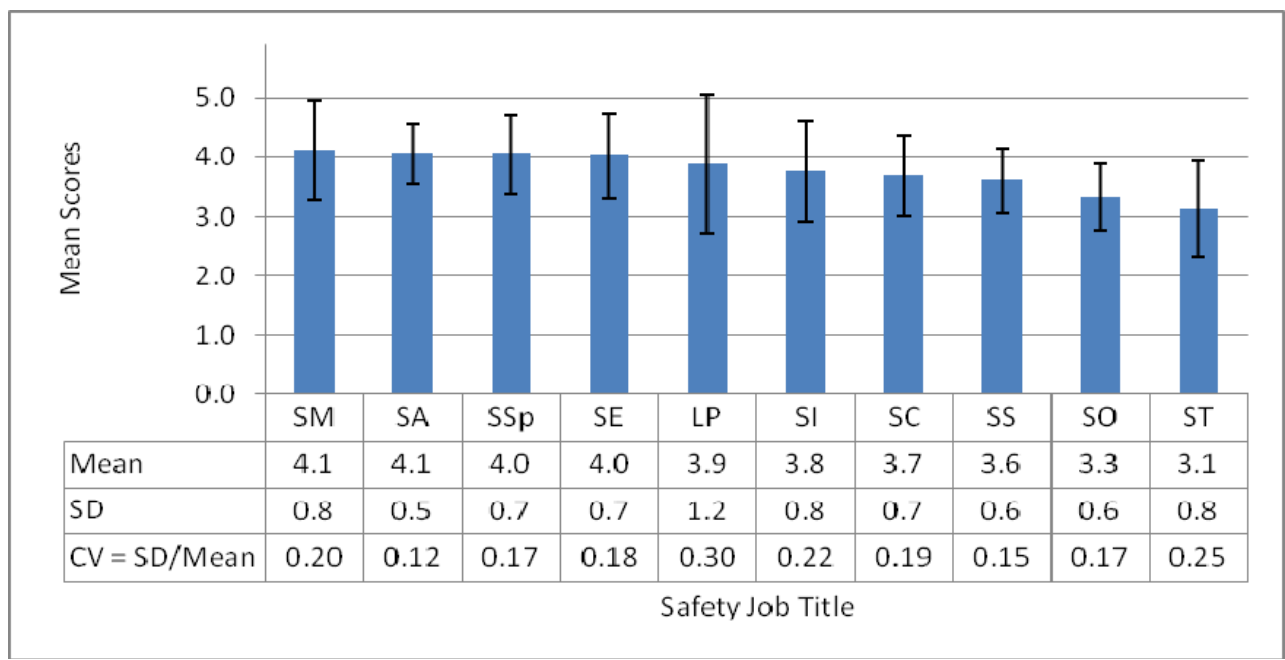

Figure 3. Mean overall scores of job descriptions according to safety job title 
In general, the component INFO was best described in the job descriptions of the job titles

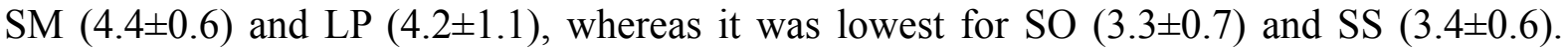
The quality of the component ROLE was better for the job titles SS (4.8 \pm 0.4$)$, followed by SA, SE, SSp, SI, LP, SM and SC (from 4.2 to 4.7), and finally SO (3.6 \pm 1.3$)$ and ST (3.2 \pm 1.3$)$. The component QUAL was best described for the job titles SM, SA and SSp (mean score = 3.7) and worst for the job titles SS and ST (mean score $=2.6$ ).

\subsection{Evaluation of Job Description Components According to Required Years of Experience}

Figure 4 shows that there are positive linear correlations between years of experience required for the safety jobs and the mean scores of job descriptions quality. The correlation was significant for the job description components INFO $\left(R^{2}=0.1296, P\right.$-value $\left.=0.002\right)$, QUAL $\left(R^{2}=0.4146, P\right.$-value $\left.<0.001\right)$ and overall mean scores $\left(R^{2}=0.2187, P\right.$-value $<$ $0.001)$. However, it was insignificant with the scores of the ROLE component $\left(R^{2}=0.007\right.$, $P$-value $=0.494)$.
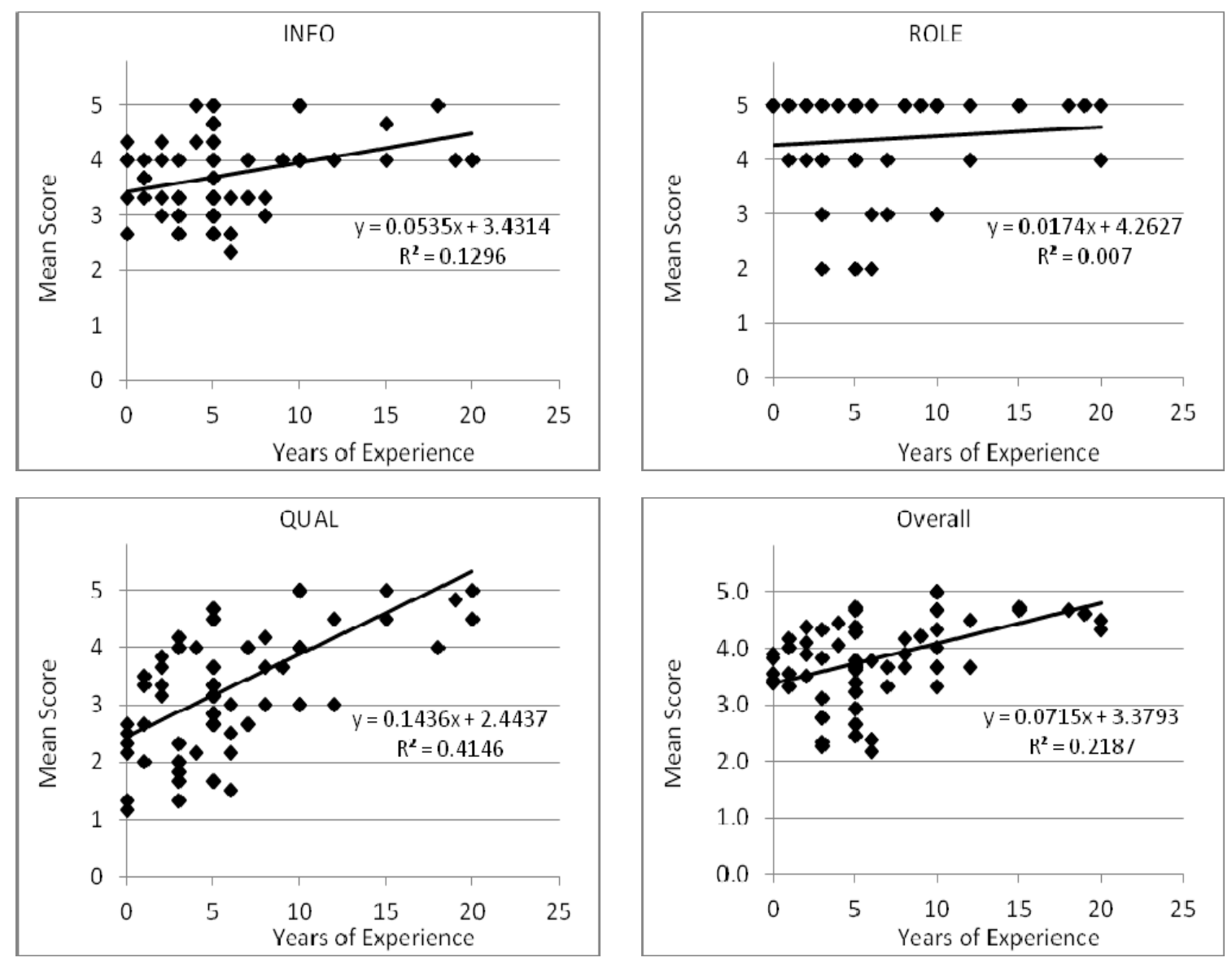

Figure 4. The relationship between the required years of experience for safety jobs and mean scores of job description components

These positive correlations indicate that the Saudi companies give more attention in designing job descriptions of the safety positions requiring longer experience. An explanation of this may be that the jobs with longer experience are associated with important roles and 
responsibilities that have an impact on the companies and, consequently, are highly paid. Hence, the companies will be eager to hire highly qualified safety professionals for these jobs. To achieve this, the companies have to well-design the job description, particularly the QUAL component.

\section{Conclusions}

This study investigated the quality of job descriptions of safety jobs in the Saudi companies. A total of 69 job descriptions were studied to explore the factors that may influence the quality of job description design. Overall, there were some gaps in the design of the job descriptions of safety jobs. Although the roles and responsibilities were, relatively, well-written in the sampled job descriptions, the other components, i.e., job information and required qualifications, were poorly designed in most of the job descriptions. The poorly-designed job descriptions of safety jobs may have a negative impact on the OSH performance of the Saudi industrial and service sectors for several reasons. Firstly, this will limit the chance of hiring highly qualified safety professionals who are vital to the success of OSH management systems in organizations. Secondly, the relationship between the presence of qualified safety professionals and the safety culture (and performance) in an organization is a two-way relationship. In other words, poor safety culture results in hiring unqualified safety professionals which, in turn, will negatively impact the safety culture in a non-ending cycle. Thirdly, the low quality of job descriptions will not allow for exploring the proper competencies that the safety professionals should have before joining the jobs. This will make the safety professional uncertain of what level of safety education or training and which skills he should attain. Furthermore, the educational institutes will have insufficient information about these competencies to consider them in the safety programs curricula.

The current study reveals that the most important factors that had an impact on the quality of the sampled job descriptions of safety jobs were the industrial sector and the required years of experience, regardless of the job title or level. Despite having some gaps, the oil \& gas, petrochemicals and utility sectors had better-designed job descriptions than other sectors. It is recommended that their practices be publicized for the benefit of the other sectors.

It is worth mentioning that the Saudi Ministry of Civil Service publishes the catalogue of the job descriptions of all governmental jobs. It is highly recommended that the Ministry pays attention to safety positions' job descriptions. Their models of job descriptions may be worthy to be followed by the private sector if well-prepared.

The current study has one limitation that should be considered. Due to less than expected response rate from industries, the sample size was not large enough to generalize the results of the study. However, the results were interpreted in light of some recently published research about the OSH performance of several sectors in Saudi Arabia, where the agreement was found in many cases. It is recommended, therefore, that a larger sample of job descriptions of safety jobs be studied and the impact of other potential factors on the quality of job descriptions be investigated. Other qualitative and quantitative methods for analysis may also be utilized in future studies. 


\section{References}

Aburass, M. (2018). Occupational safety and health risk assessment and management in Distribution Engineering Department of Saudi Electricity Company. Dissertation, King Abdulaziz University.

Ahmad, I., Balkhyour, M. A., Abokhashabah, T. M., Ismail, I. M., \& Rehan, M. (2017). Workplace Safety and Health Conditions and Facilities in Small Industries in Jeddah, Saudi Arabia. Journal of Safety Studies, 3(1), 37-52. https://doi.org/10.5296/jss.v3i1.11104

Al Haadir, S., \& Panuwatwanich, K. (2011). Critical success factors for safety program implementation among construction companies in Saudi Arabia. Procedia engineering, 14, 148-155. https://doi.org/10.1016/j.proeng.2011.07.017

Alasamri, H., Chrisp, M. T., \& Bowles, G. (2012, September). A framework for enhancing and improving the safety culture on Saudi construction sites. In Procs 28th Annual ARCOM Conference, Association of Researchers in Construction Management (pp. 3-5).

Al-Darrab, I. A., Gulzar, W. A., \& Ali, K. S. (2013). Status of implementation of safety, quality and environmental management systems in Saudi Arabian industries. Total Quality Manag. \& Bus. Excellence, 24(3-4), 336-354. https://doi.org/10.1080/14783363.2012.733257

Al-Ghamri, N. S. (2017). Occupational Health and Safety in Small Enterprises: A Field Study in the Western Region of Saudi Arabia. International Business Research, 10(10), 182. https://doi.org/10.5539/ibr.v10n10p182

Alolah, T., Stewart, R. A., Panuwatwanich, K., \& Mohamed, S. (2014). Determining the causal relationships among balanced scorecard perspectives on school safety performance: Case of Saudi Arabia. Accident Analysis \& Prevention, 68, 57-74. https://doi.org/10.1016/j.aap.2014.02.002

Al-Qubaisi, M.F. (2016). Study Occupational Injuries and Safety Culture in Saudi Electricity Company - Western Region. Dissertation, King Abdulaziz University.

Alsubaie, A. S. (2017). School safety and emergency preparedness in Saudi Arabia: a call for effective action. International journal of research in medical sciences, 5(4), 1176-1179. https://doi.org/10.18203/2320-6012.ijrms20171221

Bakker, A. B., \& Demerouti, E. (2007). The job demands-resources model: State of the art. J. of Managerial Psychology, 22, 309-328. https://doi.org/10.1108/02683940710733115

Bakker, A. B., \& Demerouti, E. (2014). Job demands-resources theory. Wellbeing. 3:2:3:1-28. https://doi.org/10.1002/9781118539415.wbwel1019

Blair, E. H. (2004, January). Critical competencies for SH\&E managers-implications for educators. In ASSE Professional Development Conference and Exposition. American Society of Safety Engineers.

Chang, S. H., Chen, D. F., \& Wu, T. C. (2012). Developing a competency model for safety 
professionals: Correlations between competency and safety functions. Journal of safety research, 43(5), 339-350. https://doi.org/10.1016/j.jsr.2012.10.009

Cox, S. \& Cox, T. (1991). The structure of employee attitudes to safety - a European example. Work and Stress, 5, 93-106. https://doi.org/10.1080/02678379108257007

Cushway, B. (2008). The handbook of model job descriptions. Kogan Page Publishers, London, UK.

Gan, M., \& Kleiner, B. H. (2005). How to write job descriptions effectively. Management Research News, 28(8), 48-54.

Hackman, J. R., \& Oldham, G. R. (1976). Motivation through the design of work: Test of a theory. Organizational behavior and human performance, 16(2), 250-279. https://doi.org/10.1016/0030-5073(76)90016-7

Hackman, J. R., \& Oldham, G. R. (1980). Work redesign. Reading, MA: Addison-Wesley.

Hall-Ellis, S. D. (2006). Descriptive impressions of managerial and supervisory cataloger positions as reflected in American Libraries, AutoCAT, and the Colorado State Library Jobline, 2000-2004: A content analysis of education, competencies, and experience. Cataloging \& classification quarterly, 42(1), 55-92. https://doi.org/10.1300/J104v42n01_06

Hassanain, M. A., \& Al-Mudhei, A. (2006). Fire safety evaluation of motor fuel dispensing facilities. Structural Survey, 24(1), 65-76. https://doi.org/10.1108/02360800610654423

Humphrey, S. E., Nahrgang, J. D., \& Morgeson, F. P. (2007). Integrating motivational, social, and contextual work design features: a meta-analytic summary and theoretical extension of the work design literature. Journal of Applied Psychology, 92 (5), 1332-1356. https://doi.org/10.1037/0021-9010.92.5.1332

Jerabek, A. (2003). Job descriptions: Don't hire without them. Journal of interlibrary loan, document delivery \& infor. supply, 13(3), 113-126. https://doi.org/10.1300/J110v13n03_07

Kadasah, N. A. (2015). An Assessment of the Occupational Health and Safety Environment among Organizations on the Light of OHSAS 18001: The Case of Saudi Arabia. International Journal of Business and Social Science, 6(4).

Leemann, J. E. (2005). Delivering business value by linking behavioral EHS competencies to corporate core competencies. Int J Sustainable Business, 12, 3-16.

Morgeson, F. P., \& Humphrey, S. E. (2006). The Work Design Questionnaire (WDQ): developing and validating a comprehensive measure for assessing job design and the nature of work. J. of applied psy., 91(6), 1321-1339. https://doi.org/10.1037/0021-9010.91.6.1321

Mosly, I. (2015). Safety Performance in the Construction Industry of Saudi Arabia. Int. J. of Construction Eng. \& Man., 4(6), 238-247. https://doi.org/10.5923/j.ijcem.20150406.03

Noweir, M. H., Alidrisi, M. M., Al-Darrab, I. A., \& Zytoon, M. A. (2013). Occupational safety and health performance of the manufacturing sector in Jeddah Industrial Estate, Saudi 
Arabia: A 20-years follow-up study. Safety science, 53, 11-24. https://doi.org/10.1016/j.ssci.2012.09.005

Park, J. R., Lu, C., \& Marion, L. (2009). Cataloging professionals in the digital environment: A content analysis of job descriptions. Journal of the Association for Information Science and Technology, 60(4), 844-857. https://doi.org/10.1002/asi.21007

Pitt, R., \& Mewburn, I. (2016). Academic superheroes? A critical analysis of academic job descriptions. Journal of Higher Education Policy and Management, 38(1), 88-101. https://doi.org/10.1080/1360080X.2015.1126896

Rohr, S.L. (2016). Harnessing the power of the job description. Human Resource Manag. International Digest, 24(6), 8-11. https://doi.org/10.1108/HRMID-09-2015-0143

Smith, K. J. (2015). Conducting Thorough Job Analyses and Drafting Lawful Job Descriptions. Employment Relations Today, 41(4), 95-99. https://doi.org/10.1002/ert.21479

Suresh, S., Renukappa, S., Alghanmi, I., Mushatat, S., \& Olayinka, R. (2017). Examining the Satisfaction Level of Construction Workers Regarding Safety Management in the Kingdom of Saudi Arabia. Journal of Construction in Developing Countries, 22(1), 97-113. https://doi.org/10.21315/jcdc2017.22.1.6

Taylan, O., Zytoon, M. A., Morfeq, A., Al-Hmouz, R., \& Herrera-Viedma, E. (2017). Workplace assessment by fuzzy decision tree and TOPSIS methodologies to manage the occupational safety and health performance. Journal of Intelligent \& Fuzzy Systems, 33(2), 1209-1224. https://doi.org/10.3233/JIFS-17043

Teare, J., Horne, M., Clements, G., \& Mohammed, M. A. (2017). A comparison of job descriptions for nurse practitioners working in out-of-hours primary care services: implications for workforce planning, patients and nursing. Journal of clinical nursing, 26(5-6), 707-716. https://doi.org/10.1111/jocn.13513

Tweeddale, H. M. (2001). Nourishing and poisoning a 'safety culture'. Process Safety and Environmental Protection, 79(3), 167-173. https://doi.org/10.1205/09575820150511948

Weiss-Gal, I., \& Levin, L. (2010). Social workers and policy practice: An analysis of job descriptions in Israel. Journal of Policy Practice, 9(3-4), 183-200. https://doi.org/10.1080/15588742.2010.487248

$\mathrm{Wu}, \mathrm{T}$. C. (2004). Measuring safety culture of labs in universities and colleges. Journal of Occupational Safety and Health, 12, 315-327.

Wu, T. C., Lin, C. H., \& Shiau, S. Y. (2010). Predicting safety culture: The roles of employer, operations manager and safety professional. Journal of safety research, 41(5), 423-431. https://doi.org/10.1016/j.jsr.2010.06.006

Wu, T. C., Liu, C. W., \& Lu, M. C. (2007). Safety climate in university and college laboratories: Impact of organizational and individual factors. Journal of Safety Research, 38(1), 91-102. https://doi.org/10.1016/j.jsr.2007.01.003 


\section{Macrothink}

\section{Glossary}

CON: Construction sector

EDU: Education/training sector

INFO: Job information

LP: Loss prevention engineer

MAN: Manufacturing sector

OGS: Oil \& gas sector

PET: Petrochemicals sector

QUAL: Job qualifications

ROLE: Job roles and responsibilities

SA: Safety advisor

SC: Safety coordinator

SE: Safety engineer

SI: Safety inspector

SM: Safety manager

SO: Safety officer

SRD: Service/retail/distribution sector

SS: Safety supervisor

$\mathrm{SSp}$ : Safety specialist

ST: Safety trainer

UTL: Utility sector

\section{Copyright Disclaimer}

Copyright for this article is retained by the author(s), with first publication rights granted to the journal.

This is an open-access article distributed under the terms and conditions of the Creative Commons Attribution license (http://creativecommons.org/licenses/by/3.0/). 